\title{
Form of Public Service Innovation in toward Future of Government in Surabaya City: Study of the "6 in 1" Population Administration Program
}

\author{
Trenda Aktiva Oktariyanda ${ }^{1}$, Fitrotun Niswah ${ }^{2}$, Badrudin Kurniawan ${ }^{3}$. \\ \{trendaoktariyanda@unesa.ac.id ${ }^{1}$, fitrotunniswah@unesa.ac.id ${ }^{2}$, badrudinkurniawan@unesa.ac.id ${ }^{3}$ \} \\ Department of Public Administration, Universitas Negeri Surabaya ${ }^{123}$
}

\begin{abstract}
Governments and public sector organizations face a future where dealing with uncertainty while delivering services that are fast, affordable, and innovative, in the context of the Industrial Revolution 4.0 and even during this unexpected Covid-19 pandemic. One of the Surabaya City Government public service innovations is the "6 in 1" program which includes the management of birth certificates, deaths, marriages, divorces, moving letters of arrival, and moving out online. The purpose of this study is to describe and analyze the innovations of the "6 in 1" program by the Surabaya Population and Civil Registry Service office. This type of research used in this research is descriptive with a qualitative approach. From the results of this study, it is found that the components of Governance and Innovation, Sources of The Ideas for Innovation, Innovation Culture, Capabilities and Tools, Objectives Outcomes Drivers and Obstacles, and Collecting Innovation Data for Single Innovations have been running quite well and there are no significant obstacles. Based on the research results, it is known that the innovation of the "6 in 1" program fulfills the elements of research focus according to Bloch \& Bugge, although it is still not fully optimal.
\end{abstract}

Keywords: Future of Government, Public Service Innovation, Population Administration, "6 in 1" Program.

\section{Introduction}

As we know, the world can still be "lit" today and in the future, if science and technology as its "axis and container" are always vibrant, developing, innovating, even revolution and evolution are inevitable. Reinforced by the technology insurgence [1], advanced Darwinism has kept on reshape socio-economic needs and advance circumstances where governments are constrained into actualizing greater alter programs than ever sometime recently [2]. Customarily, a government is outlined to convey administrations and policies [1]. However, such work has advanced within the past 20 years and the impact of Information and Communication Innovation (ICT) has been overwhelming constrain in such advancement. Consequently, making strides of operational efficiencies is inserted as the center ethos of present-day governments [3]. In this setting, governments are anticipated to plan an approach that empowers advanced change through the usage of ICT-led arrangement instruments [4]. 
Innovations in ICT offer wealthy openings for governments to essentially progress the conveyance of their administrations and to associated more straightforwardly with their constituents [5]. Present-day ICT too offers the government numerous promising openings to speed up work forms, increment the adequacy and efficiency of approach, offer superior and more customized administrations, and help the stack of bureaucracy [6]. High-quality encounters with responsive, coordinates private division data frameworks have driven citizens to anticipate the same sorts of involvement from public bodies and offices [7]. Thus, citizens and businesses are requesting more viable and proficient conveyance of administrations, as well as an enhancement within the quality of data, gotten [8].

As seen over, Numerous analysts highlight ICT's part in and affect on the advance of human history after the Industrial Revolution [9]. The rapid development of information and communications technologies (ICTs) evokes the paradigm shift of human society. Technologies, best understood as a means of better communication, improved processing, and exchange of information, now impact every aspect of our lives, constantly revolutionizing the way we communicate with each other, comprehend our environments, and interact with government. ICTs have played an important role in fostering improved connectivity as well as socio-economic development throughout the world [10]; [11].

In our view, tomorrow's public body will need to act quite differently, more like a living organism, adapting to change and evolving to address society's needs as they develop. Governments and public sector leaders have a key role in this shift, refocusing their organizations on their changing environments and projecting a clear and vibrant picture for the future which energizes both their internal and external stakeholders. For this to happen, several elements need to be aligned to create the desired public body of the future, one that is adaptive to its circumstances and ready to deliver its defined purpose in the face of a world in constant change [12] (see Figure 1).

\begin{tabular}{|l|l|}
\hline From... & To... \\
\hline Citizen under control & Citizen in control \\
\hline Governing for citizens & Governing with citizens \\
\hline Organisation silos & Organisation networks \\
\hline $\begin{array}{l}\text { Public sector organisations as big, } \\
\text { all-in-one giants }\end{array}$ & $\begin{array}{l}\text { Public sector organisations as small, flexible, } \\
\text { purpose-driven entities }\end{array}$ \\
\hline Government as service provider & $\begin{array}{l}\text { Government as service facilitator/ broker/ } \\
\text { commissioner }\end{array}$ \\
\hline Government owning inputs and processes & Governments and citizens owning outcomes \\
\hline Measuring outputs & Measuring outcomes \\
\hline Forced cooperation based on enforcement & Mutual collaboration based on trust \\
\hline Trust in the 'strong leader' & Trust in each other, the 'servant leader'
\end{tabular}

Fig. 1. Bridging from now to the future [12] 
Talking about the future of government, it becomes interesting if we look at the picture of ICT development and public service innovation in it, especially in third world countries, for example in the Republic of Indonesia. In every country, including Indonesia itself, the fulfillment of public services for the welfare of society is an absolute obligation. This is stated in the fourth paragraph of the State Goals contained in the Preamble of the 1945 Constitution, which is to promote public welfare, educate the life of the nation, and participate in implementing world order based on independence, eternal peace and social justice, the welfare of the people and the intellectual life of the nation. This statement is the way for the government to achieve the goals of the State of Indonesia by providing professional services to the community through a good government system in supporting the delivery of quality services that must be in accordance with the needs, demands and minds of the people today. The higher demands from the community, the government makes new breakthroughs to improve public services through service innovation. Public services are being promoted from various directions as a form of government commitment to improve service quality even better.

To support the creation of ideal public service innovations, the Ministry of Administrative and Bureaucratic Reform (PANRB) implements the "One Agency, One Innovation" policy. Namely every Ministry / Institution and Local Government is required to create at least one Public Service Innovation every year which will be objectively assessed in a competitive atmosphere through the Public Service Innovation Competition). The service system by developing a service innovation, with this it is expected that the quality of performance of the apparatus, especially in the field of accelerating public services. This is because public services are an important aspect of people's lives. One of the innovations in this field, such as that created by the Government of the Surabaya City Population and Civil Registry Service, is the 6 in 1 program, the Surabaya City Population and Civil Registry Office "6 in 1 program" was nominated for the Top 40 of the Public Service Innovation System (Sinovik) of the Ministry of State Apparatus Empowerment and Bureaucratic Reform (Kemenpan RB) [13]. The 6 in 1 program was chosen because this program was a new and only current public service innovation. In this 6 in 1 program, although new, it has several advantages in service. One of them is the e-Lampid application which provides an economical package service to manage several documents simultaneously in order to save time and effort. Service package 1 is service for birth certificates and family cards, service package 2 is service for death certificates and family cards, service package 3 is service for incoming mail and family cards.

Surabaya is one of the big cities in Indonesia. The population reaches 3 million. The area is around 33,451.14 hectares. There are 31 subdistricts and 154 sub-districts in this city. From such a large number of residents, every day there are many requests for population administration services at the Population and Civil Registration Service. The Surabaya City Population and Civil Registry Officel is a unique institution. This is because all residents of Surabaya need services here, from the time they were born until they died. The management of population administration in this service has always been large. In particular, on six types of population services. Namely, services for moving in, moving out, birth certificates, death certificates, marriage, and divorce. The high number of population file arrangements at Surabaya City Population and Civil Registry Office has created a number of problems.

One of the problems that occurs is the volume of queues at the Population and Civil Registry Service is always busy every working day. Every day the District Head Office 
receives more than 411 requests from six service items: moving in, moving out, birth certificates, death certificates, marriage and divorce. This number does not include queues for other services. This resulted in the office becoming overcrowded with people making submissions. The large number of queues has led to more brokers. These brokers make the atmosphere in the District Police Office uncomfortable. The existence of brokers opens up opportunities for extortion. The cost of managing population administration that must be paid by the community has increased. The average file processing time is 7 working days after the file is declared complete. Files accumulate in the Surabaya City Population and Civil Registry Office as part of the verification process. Another problem is the poor, illiterate, disabled, elderly who have limitations, find it difficult because the number of officers in the District Head Office cannot freely accompany them. The reason is that the number of residents who take care of so many while the officers at the District Head Office are relatively limited.

These problems are resolved with 6 in 1 Innovation (Management of Moving In, Moving Out, Birth, Death, Marriage, and Online Divorce Certificates). The 6 in 1 innovation was sparked by good intentions to provide easy access to public services in the field of population administration. Therefore, the positive impact that is felt will definitely hit the community as a whole. The City Government also benefits from the optimization of bureaucratic reform. All services are more effective and efficient. Benefits for society include efficiency in time, energy and costs. People no longer need to come to the Surabaya City Population and Civil Registry office.

Although the implementation of the 6 in 1 program in the City of Surabaya aims to make it easier for the public to take care of moving in, moving out, birth, death, marriage, and online divorce certificates, it is undeniable that there are still many people who do not know the program so that the benefits of this program cannot be felt by the entire community of Surabaya City. Therefore, the Surabaya City Government must be more extensive in disseminating this 6 in 1 program to all residents of the City of Surabaya so that its use can be felt by all its citizens. Not only introducing the program, but the socialization of how to use the program must be clear so that the community is not confused in its implementation later. It is hoped that with this innovation the quality of service will be even better. So the formulation of the problem in this study is how to implement the "6 in 1" Population Administration Program as a form of public service innovation which is one of the keys of the future of government in Surabaya. 


\section{Methodology}

This type of research used in this research is descriptive with a qualitative approach. The focus of this research is the theory of the success factors of innovation according to Bloch \& Bugge [14]. Key factors influenced by the innovation process in the public sector. The subjects of this study used a purposive sampling technique. The data collection technique in this research is through literature study and documentation study. Meanwhile, the data analysis technique uses qualitative data analysis used by Miles, Huberman, and Saldana [15] which consists of four stages, namely data collection, data reduction, data presentation and drawing conclusions or verification. The stages of data reduction, data presentation and conclusion drawing are a series of analysis activities through an interactive cycle process.

\section{Results and Discussion}

Public Service 6 In 1 Online or E-Lampid is an innovation from government agencies of the Surabaya City Population and Civil Registration Service which tries to provide the best service regarding births, deaths, moving in, moving out, marriage and divorce. Based on the results of this study, an analysis of the 6 In 1 Online or E-Lampid Public Service innovation can be carried out at the Surabaya City Regional Office of the Regional Public Service Office using the theory of the success factor of innovation according to Bloch \& Bugge [14]. These theories include Governance and Innovation, Sources of The Ideas for Innovation, Innovation Culture, Capabilities and Tools, Objectives Outcomes Drivers and Obstacles, and Collecting Innovation Data for Single Innovations.

a. Governance and Innovation

The Department of Population and Civil Registry of the City of Surabaya explained the requirements for issuing birth certificates, death certificates, moving in, moving out, marriage and divorce. Then, work together to identify the verification process in the government administration and regional autonomy as coordinator of sub-districts / villages throughout Surabaya. This innovation has made the village and sub-district parties at the forefront of interacting and dealing directly with the community. Surabaya City Civil Information and Communication Office is in charge of making an online application that can be used for registration and verification according to the needs of the District Head Office with the website lampid.surabaya.go.id.

The equipment administration section is in charge of the procurement of supporting tools. The equipment in question is the provision of a Broadband Learning Center (BLC) which contains free internet access devices such as wifi and e-Kios that can access a number of Surabaya City Government programs with an internet-based touch screen model. At present, BLC and E-Kios have been placed in Sub-district, District and Public health center offices. People who experience problems can immediately consult with village / sub-district 
officers or employees and get answers to these problems in a comprehensive manner.

Some of the problems that occur in the Surabaya City Population and Civil Registration Service are the existence of illegal fees, illegal brokers, confusing requirements, and long queues. With the 6 in 1 Online Service Program, people do not need to queue long, brokers and illegal fees are eliminated by themselves, the process of processing can be easier and shorter. This is because file processing or verification can be done in sub-districts and districts, and the officers there have adjusted the ratio to the population in that area. The concept of this innovation is an online "walking file". With the 6 in 1 public service program, people who wish to take care of incoming transfer letters can carry out the file registration process and upload files while still in their area of origin. This condition makes it easier for those who are outside the city.

b. Sources of The Ideas for Innovation

The focus of this research shows that the source of the innovation of the "6 in 1" population administration program is none other than the leaders who are at the city level and are supported by the leaders above it. With that, there is no doubt that the "6 in 1" population administration program has received awards up to the national level. This is evidenced by the statement of Mr. Suharto Wardoyo as Head of the Surabaya City Population and Civil Registry Office, stating that the innovation of the "6 in 1" e-Lampid program, the result of a collaboration between the Population and Civil Registry Office and the Surabaya City Information and Communication Office, has successfully penetrated the Top 40 Innovations Indonesian Public Service (beritajatim.com, 2019).

Through this innovation, people only need to upload or upload files online. Verification for birth and death certificate services is sufficient in the subdistrict. Meanwhile, verification for incoming and outgoing mail services can only be done at the sub-district office. The process or status of online files that have been sent can be monitored online. There are no more files stuck or "hanging" in the middle of the road without a known cause. Citizens and the City Government can monitor each stage of the process through the "status" feature on the lampid.surabaya.go.id web page. Not only through PCs or laptops, and e-kiosks, this innovation can also be run from gadgets / cellphones / smart phones.

c. Innovation Culture

The e-lampid application system was tested. Training and assistance to officers in the Sub-district office / District office are carried out. This training and mentoring was carried out by the Department of Population and Civil Registration and the Office of Communication and Information of the City of Surabaya. This is because those who understand technical services are the Department of Population and Civil Registry, while those who understand technical applications are the Communication and Information Office. The implementation of this program is executed. Maintenance activities or maintenance and repair of the e-Lampid application are continuously carried out. The development of the e-Lampid application also continues. Application 
development will be carried out so that there will be more internet-based services.

d. Capabilities and Tools

1) Human Resources

The human resources involved in implementing this innovation come from within the Surabaya City Government. They come from a number of Regional Apparatus Organizations, namely the Population and Civil Registration Service, the Communication and Information Technology Office, the Equipment Administration Section, the Government Administration and Regional Autonomy Section, and the Sub-district office / District office. Members of the Regional Apparatus Organization carry out tasks in their respective fields. Starting from the planning stage, program design, testing, implementation and development. The external human resources of the Surabaya City Government are the mass media crews who are invited to participate in the socialization of this program to the public. This is because this new innovation was not widely recognized by the people of Surabaya at first.

\section{2) Tool Resources}

The tool resource used to make this innovation a success is the Broadband Learning Center (BLC). Until now, BLC is located in almost all subdistricts, districts, flats and city parks of Surabaya. Procurement of BLC is carried out by the Equipment Administration Division and is fully supported by PT Telkom. In addition, this innovation is also supported by e-Kiosk equipment. E-Kios are scattered in Sub-district / District / Public health center offices and other government offices. BLC and e-Kios are support tools for those without internet access. However, this innovation can be accessed anywhere in the country. In particular, for those who wish to move to Surabaya.

3) Funding

To support the Innovation program, the City Government has disbursed Regional Revenue and Expenditure Budget funds from 2014 to this year and the following years. This budget includes the provision of BLC and eKios throughout Surabaya as well as the tools used to support this innovation, such as computers and other supporting tools.

e. Objectives Outcomes Drivers and Obstacles

The goal is something that must be achieved in public service innovation, results are something that is achieved as long as this public service innovation is implemented, drivers are a source of funds and obstacles are obstacles during the implementation of the public service innovation. The goal of the 6 in 1 Online Public Service innovation is to provide easy access to public services in the field of population administration. Therefore, the positive impact that is felt will definitely hit the community as a whole. The City Government also benefits from the optimization of bureaucratic reform. All services are more effective and efficient. 
Benefits for society include efficiency in time, energy and costs. People no longer need to come to the Population and Civil Registry Office. For birth and death certificate services, file verification is sufficient at the village office once. For incoming and outgoing mail services, verification is sufficient at the sub-district office. The result of the innovation of the 6 in 1 Online Public Service is that population administration services can be accessed from the home or the village office which is certainly not far from home. Initial verification has been carried out since in front of the internet screen. So, incomplete files can be immediately identified and can be completed immediately in the Sub-district office / District office. Citizens do not need to go back and forth to confirm. Drivers or sources of funds are free of charge to access the e-Lampid application. The community does not incur transportation costs to go to the Population and Civil Registry Office.

The obstacle to the service innovation is that the implementation of this innovation encountered a number of obstacles. For example, in connection with the paradigm of some people who are still comfortable with offline methods because they have been used to it for a long time. They are still comfortable with the old method. The solution to this problem is to provide an understanding of the ease of managing citizen administration online. Good ease that can be felt now, as well as in the future, if you want to take care of deeds or other documents. He also conveyed that online management will save time, effort and cost. Another obstacle to this innovation is the delivery of the completed birth certificate or death certificate. To be precise, the applicant's address on the Family Card is different from the domicile address. One example, there are residents who rent a house in the Rungkut area to approach the workplace. Meanwhile, the address on the Family Card is the Perak area and the files are sent to Perak. If this is the case, the solution is that the completed deed will be deposited in the Sub-district office. Since the beginning of file processing or verification, the applicant will also be informed, if the person concerned is not at home, the certificate will be delivered to the local urban village. The problem is that this deed is confidential so that it cannot be accepted by just anyone.

f. Collecting Innovation Data for Single Innovations

The success of this 6 in 1 innovation provides a lot of lessons. One of them, is the importance of taking advantage of advances in information and communication technology for bureaucratic reform. This step makes public services more effective and efficient.

In addition, the launch of this program shows the importance of togetherness and synergy between Regional Apparatus Organizations (OPD). The development of this application eliminates sectoral egos among DPOs. This is because coordination and division of tasks are required among a number of OPDs, in this case the Population and Civil Registry Office, the Communication and Information Office, the Equipment Administration Section, the Government Administration and Regional Autonomy Section, and the Subdistrict office / District office. Cooperation between DPOs from the top level to the lowest level that has direct contact with the community is an absolute necessity. For the success of this public service innovation. 
Other lessons learned relate to efforts to change the mindset of government officials and the public regarding the use of technology to optimize public services. Conventional and "offline" models must begin to be abandoned as a form of response to the challenges of the times. In this way, significant savings in time, effort and costs can be achieved.

\section{Conclusion and Suggestion}

a. Conclusion

Based on the implementation of the Surabaya City 6 In 1 Online Public Service innovation with the theory of innovation success factors according to Bloch \& Bugge [14]. These theories include Governance and Innovation, Sources of The Ideas for Innovation, Innovation Culture, Capabilities and Tools, Objectives Outcomes Drivers, and Obstacles (Objectives, Results, Drivers, and Barriers) and Collecting Innovation Data For Single Innovations (Collecting Innovation Data for Single Innovations) both in providing services to the community.

On the other hand, Surabaya City Civil Information and Communication Office is always ready at any time to respond to complaints if there are problems related to systems or applications. So far, complaints or suggestions from internal city government officials, including the District Head of Regional Office, have always been taken into consideration for the improvement of the online application system. Surabaya City Civil Information and Communication Office also opens a social control room through an internet-based Media Center, social media, fax, and telephone. The Media Center is a space for Surabaya residents who want to convey criticism, suggestions, and input regarding the performance of the Surabaya City Government as a whole. Including, in it, regarding this 6 in 1 program.

The Mayor of Surabaya, Tri Rismaharini, also has access to monitor through this Media Center. So, public complaints can be directly entered or submitted to the number one person in Surabaya. So far, the Mayor has also continuously monitored and evaluated this program.

In principle, because this program is an activity that serves daily, monitoring and evaluation of the Head of the Regional Office of the Regional Office, the Head of the Department of Communication and Information, and the Mayor are also carried out daily and continuously. In addition, there is also an annual evaluation at the end of each fiscal year. The annual evaluation was also carried out together with the Surabaya Regional People's Representative Council. Board members often provide input on the sustainability of this innovation. They also get detailed information about the innovation program from constituents. So far, the members of the board have appreciated the 6 in 1 breakthrough, as conveyed by constituents to them.

There are several obstacles to implementing this innovation. For example, in connection with the paradigm of some people who are still comfortable with offline methods because they have been used to it for a long time. They are still comfortable with the old method. Another obstacle to this innovation is the 
delivery of the completed birth certificate or death certificate. To be precise, the applicant's address on the Family Card is different from the domicile address.

b. Suggestion

Based on the 6 In 1 Online or E-Lampid Public Service innovation in its implementation, we provide suggestions to make it better for the future:

1) There needs to be increased socialization regarding the use of web pages such as how to register, verify, and take deeds, etc. to people who want to manage files so that this new innovation can be well realized.

2) There is a need for notification and procedures regarding the standard operating procedure (SOP) for the use of this web page to the people of Surabaya in order to know the implementation procedure of the web.

3) Increasing staff at Sub-district government office / Public health center offices who can provide direction to people who do not understand the use of the ELampid application so that they can understand how to use the application on gadgets or from home. So, they don't have to come to the office just to take care of their needs through the Broadband Learning Center (BLC) or E-Kiosk.

4) Increase socialization to the public about the benefits obtained from using the ELampid application because there are still people who use the offline method to take care of administrative needs at the office. For example, the benefits that can be felt by using the E-Lampid application are saving costs, time and energy.

\section{References}

[1] Briggs, B., Buchholz, S., Sharma, S., Saif, I., \& Mossburg, E. (2019). Tech Trend 2019: Beyond the Digital Fromtier (p. 14).Deloitte Development LLC. Retrieved from https:// www2.deloitte.com/content/dam/Deloitte/br/Documents/technology/DI_TechT rends2019.pdf.

[2] Omar, A., Weerakkody, V., \& Sivarajah, U. (2017). Digitally enabled service transformation in UK public sector: a case analysis of universal credit. International Journal of Information Management, 37(4), 350-356. https://doi.org/10.1016/j.ijinfomgt.2017.04.001.

[3] Mahmood, M., Weerakkody, V., \& Chen, W. (2019). The influence of transformed government on citizen trust: insights from Bahrain. Information Technology for Development, 25(2), 275-303.

[4] Waller, P., \& Weerakkody, V. (2016). Digital Government: overcoming the systemic failure of transformation. Retrieved 17 November 2019 https://bura.brunel.ac.uk/handle/2438/12732.

[5] Irani, Zahir., Love, Peter E.D., Montazemi, Ali. (2007). e-Government: past, present and future. European Journal of Information Systems. 16(2), 103105.doi:10.1057/palgrave.ejis.3000678.

[6] Prins, J.E.J., Broeders, Dennis., Griffioen, H.M. (2012). iGovernment: a new perspective on the future of government digitisation. Computer Law \& Security Review 28 (2012) 273-282.

[7] Hazlett, SA and Hill, F. (2003). E-government: the realities of using IT to transform the public sector. Managing Service Quality 13(6), 445-452. 
[8] Ongaro, E. (2004). Process management in the public sector: the experience of one-stop shops in Italy. International Journal of Public Sector Management 17(1), 81-107.

[9] Northrop, A. (2000). The information age: Which countries will benefit? In G. D. Garson (Ed.), Handbook of public information systems (pp. 265-280). NY: Marcel Dekker.

[10] Jin, S. K., \& Cho, J. M. (2015). Is ICT a new essential for national economic growth in an information society? Government Information Quarterly, 32(3), 253-260.

[11] UNESCAP. (2011). Primer 1: An introduction to ICT for development. Retrieved from http://www.unapcict.org/ecohub/primer-1-an-introduction-toict-for-development.

[12] PwC. (2013). Future of Government. PwC Report. Retrieved from https://www.pwc.com/gx/en/psrc/publications/assets/pwc_future_of_governme nt_pdf.pdf

[13] Baihaqi, Amir. (2018). 6 in 1 Dispenduk Surabaya Tembus Top 40 Inovasi Pelayanan KemenPAN RB. Retrieved from https://news.detik.com/berita-jawatimur/d-4282086/6-in-1-dispenduk-surabaya-tembus-top-40-inovasi-pelayanankemenpan-rb.

[14] Bloch, C., \& Bugge, M. M. (2013). Public Sector Innovation-From Theory to Measurement. Structural Change and Economic Dynamics, 27(2013), 133145. doi:10.1016/j.strueco.2013.06.008.

[15] Miles, M.B,. Huberman, A.M,. and Saldana, J. (2014). Qualitative Data Analysis, A Methods Sourcebook, Edition 3. USA: Sage Publications. 